\title{
Developmental activities and the acquisition of superior anticipation and decision making in soccer players
}

\section{André Roca , A. Mark Williams \& Paul R. Ford}

To cite this article: André Roca , A. Mark Williams \& Paul R. Ford (2012) Developmental activities and the acquisition of superior anticipation and decision making in soccer players, Journal of Sports Sciences, 30:15, 1643-1652, DOI: 10.1080/02640414.2012.701761

To link to this article: http://dx.doi.org/10.1080/02640414.2012.701761

电 Published online: 09 Jul 2012.

Submit your article to this journal $₫$

ЏII Article views: 1825

Q View related articles 5

Citing articles: 6 View citing articles $\square$ 


\title{
Developmental activities and the acquisition of superior anticipation and decision making in soccer players
}

\author{
ANDRÉ ROCA, A. MARK WILLIAMS, \& PAUL R. FORD \\ Research Institute for Sport and Exercise Sciences, Liverpool fohn Moores University, Liverpool, United Kingdom
}

(Accepted 5 fune 2012)

\begin{abstract}
We examined whether soccer players with varying levels of perceptual-cognitive expertise can be differentiated based on their engagement in various types and amounts of activity during their development. A total of 64 participants interacted with lifesize video clips of 11 versus 11 dynamic situations in soccer, viewed from the first-person perspective of a central defender. They were required to anticipate the actions of their opponents and to make appropriate decisions as to how best to respond. Response accuracy scores were used to categorise elite players $(n=48)$ as high- $(n=16)$ and low-performing $(n=16)$ participants. A group of recreational players $(n=16)$ who had lower response accuracy scores compared to the elite groups acted as controls. The participation history profiles of players were recorded using retrospective recall questionnaires. The average hours accumulated per year during childhood in soccer-specific play activity was the strongest predictor of perceptual-cognitive expertise. Soccer-specific practice activity during adolescence was also a predictor, albeit its impact was relatively modest. No differences were reported across groups for number of other sports engaged in during development, or for some of the key milestones achieved. A number of implications for talent development are discussed.
\end{abstract}

Keywords: expert performance, skill development, perceptual-cognitive expertise

\section{Introduction}

The ability to anticipate and make effective decisions is crucial to expert performance in soccer. Anticipation is the ability of the performer to predict what is likely to happen prior to an event occurring, whereas decision making is the ability of the performer to select and execute an appropriate action in a given situation (Williams, Ford, Eccles, \& Ward, 2011; Williams \& Ward, 2007). It is well documented that expert soccer players and athletes from other sports have demonstrated superiority over lesser skilled players in their ability to anticipate and make decisions (e.g., Helsen \& Starkes, 1999; Vaeyens, Lenoir, Williams, Mazyn, \& Philippaerts, 2007; Williams \& Davids, 1998). The ability to anticipate and make decisions is presumed to be particularly important at the elite level in soccer, where these components of performance are more likely to discriminate players compared to anthropometric and physiological characteristics (Reilly, Williams, Nevill, \& Franks, 2000; Williams \& Reilly, 2000). Most recently, researchers have started to examine how these perceptual-cognitive skills are acquired by expert athletes (e.g., Ford, Low, McRobert, \& Williams, 2010a). In this study, we extend work in this area by examining whether elite soccer players categorised as either high- or low-performing based on their performance on an interactive test film of anticipation and decision making can be differentiated based on the amount and/or type of activity undertaken during their development.

The majority of work on the nature of the acquisition processes underpinning expert performance has relied on the deliberate practice framework introduced by Ericsson, Krampe, and Tesch-Römer (1993). In this framework, retrospective recall methods (e.g., questionnaires, interviews, and training logs) are used to study the participation history profiles of expert performers in terms of the amount of hours they have spent in domain-specific activities during their development. Ericsson et al. (1993) demonstrated that the key variable in the acquisition process for musicians at the Berlin Music Academy was the amount of deliberate practice they had accumulated, which was monotonically related to their attained level of expertise. The authors classified deliberate practice as an activity designed to

Correspondence: A. Roca, Liverpool John Moores University, Research Institute for Sport and Exercise Sciences, 15-21 Webster Street, Liverpool, L3 2ET United Kingdom. E-mail: andre.roca@gmail.com 
improve a specific aspect of current performance, which requires from performers their maximum attention, effort, and concentration, including gradually refined repetitions and feedback (for reviews, see Ericsson, 2007a, 2007b; Ericsson, Nandagopal, \& Roring, 2009). After 10 years of engagement in the domain, the best violinists had accrued a greater amount of deliberate practice $(7,410 \mathrm{~h})$ compared to the good violinists $(5,301 \mathrm{~h})$ and music teachers $(3,420 \mathrm{~h})$ in support of the monotonic relationship between practice and attainment.

The retrospective recall methodology was used by Weissensteiner, Abernethy, Farrow, and Müller (2008) to examine whether differences in the ability of cricket batters to make anticipation judgments was related to their participation history profiles. Skilled and lesser skilled cricket batters from three different age groups (under 15 years, under 20 years, and adult age groups) completed a film-based temporal occlusion anticipation test, as well as a semistructured interview to retrospectively recall their participation activity histories in sport (Côté, Ericsson, \& Law, 2005). The hours accumulated in organised, cricket-specific activities (i.e., deliberate practice and competition) accounted for a relatively modest proportion (13.3\%) of the variance in performance on the anticipation test. The inclusion of participant age increased the explained variance by a further $6.9 \%$, with the skilled U20 and adult players showing superior anticipation scores compared with all other age/skill groups. The hours accumulated in informal cricket activity and formal non-sport specific practice did not explain variation in anticipation performance. The authors forwarded a number of possible explanations for the weak link between anticipation and practice, particularly the use of a single and incomplete measure of perceptual-cognitive expertise (i.e., postural cues underlying anticipatory skill).

In a similar study, Berry, Abernethy, and Côté (2008) examined the developmental activities engaged in by 32 Australian Football League (AFL) players who had been classified using coach ratings as either expert or less expert in regard to their perceptual-cognitive expertise. There were no differences evident between groups in the hours accumulated in Australian Rules football. The expert group accumulated more hours during their developing years in structured activities of all types, in structured activities involving invasion-type sports, in invasiontype deliberate play, and in invasion activities from sports other than Australian football. Superior perceptual-cognitive expertise in this sport cooccurred with greater amounts of invasion sports activity that was independent of the intent during the activity (i.e., skill development or fun) and of the specificity of the activity to the primary sport.
Weissensteiner et al. (2008) and Berry et al. (2008) used the subjective judgments of coaches to create expert and novice groups, which may be susceptible to systematic biases, such as the coachathlete relationship or the athlete's personality (for a review, see Ericsson, 2003). The selection of players into groups based on subjective criteria may lead to individuals being classified incorrectly and there would appear to be clear advantages in using objective measures of performance (Ericsson, 2003). Ford et al. (2010a) used an objective method to examine the types and amounts of developmental activities that co-occurred with superior anticipation ability in 45 elite cricket batters. The batters were stratified into high- $(n=15)$ and low-performing anticipators $(n=15)$ based on the rank order of their response accuracy scores on a film-based temporal occlusion test of anticipation. The Participation History Questionnaire (PHQ) revealed that during childhood there were no between-group differences for accumulated hours in cricket activities and other sports. However, activity differences were apparent in early adolescence, with the high-performing anticipators accumulating more hours in structured cricket activity compared to the low-performing. Moreover, the high-performing group accumulated more of their hours in structured activity in batting practice and match-like batting practice, when compared with their low-performing peers, who accumulated more of their hours in "net" activities (i.e., activity in which the batter faces a bowling machine or bowler on a wicket closely surrounded by netting and no fielders). These between-group differences in the amount of structured activity during adolescence led to the high-performing anticipators accumulating more total hours in cricket activity compared to low-performing anticipators. It appears that the structure and type of activity in which players engage (e.g., Ford, Yates, \& Williams, 2010b) as well as the amount of activity accumulated differentiates high- from low-performing anticipators.

These investigations examined the relationship between antecedent activities and anticipation ability only. There is a need to integrate and examine the antecedents of other components of expert performance such as decision making in order to provide a more complete illustration of perceptual-cognitive expertise in sports such as soccer (Williams \& Ward, 2007). The amount and type of activities that elite soccer players engage in may provide some indication of the antecedents of expert performance. Ford, Ward, Hodges, and Williams (2009; see also Ford \& Williams, 2012) examined the participation history profiles of elite soccer players in the United Kingdom who progressed to professional status at 16 years of age and those who did not. They reported that the 
elite players who went on to be offered a professional contract accumulated more hours per year in childhood in soccer-specific deliberate play, but not in soccer practice, competition or other sports compared with those who did not progress. Côté and Hay (2002) defined deliberate play (e.g., street soccer/ basketball) as an activity engaged in with the intention of fun and enjoyment, usually led by the children themselves. The two elite groups engaged in greater amounts of soccer-specific deliberate practice during childhood compared to a recreational control group, but not soccer play or engagement in other sports. The authors hypothesised that engagement in deliberate play in the primary sport during childhood may contribute to the acquisition of perceptualcognitive skills, such as anticipation and decision making. A need exists to examine the developmental activities that co-occur and may contribute to anticipation and decision making in order to create evidence for practitioners on the best way to develop these skills in young players.

In this paper, we examine whether soccer players with different levels of perceptual-cognitive expertise can be differentiated based on their engagement in various types and amounts of activity during their development. Skilled and recreational participants were required to move and interact with life-size, action sequences of 11 versus 11 soccer situations filmed from the first-person perspective of a defender. The accuracy of players in anticipating the actions of their opponents and in making decisions about how they themselves should respond was measured. Performance on the anticipation and decision making test was used to stratify participants as skilled "high-performing" and skilled "lowperforming". A third group classified as recreational performers was used as a control group. Participation history data were gathered using retrospective recall questionnaires. No between-group differences were expected for milestones achieved, such as start age in soccer (which was predicted to be around 5 years of age), supervised training in soccer, and age at which participants started playing in an organised league (Ford et al., 2009; Helsen, Starkes, \& Hodges, 1998; Ward, Hodges, Starkes, \& Williams, 2007). We expected that the average hours per year in soccerspecific practice activities during adolescence (i.e., 13-18 years of age) would be a predictor of superior anticipation and decision making performance across participants (e.g., Ford et al., 2010a; Weissensteiner et al., 2008) and would differentiate skill groups (i.e., greater amounts of this activity will co-occur with higher scores on the test as indicated by group membership). We further expected, based on the findings of Ford et al. (2009), that the average number of hours per year spent in soccer-specific play during childhood (i.e., 6-12 years of age) would be a predictor of test performance and would differentiate the skill groups. Moreover, it is likely that hours accumulated in total soccer activity by 18 years of age will differentiate skill groups (cf., Ford et al., 2010a). We assumed that the development of anticipation and decision making in soccer is mainly a result of participation in the primary sport, rather than engagement in other sports per se (e.g., Berry et al., 2008), due to the low number of other sports engaged in by soccer players during their development (e.g., Ford et al., 2009; Ward et al., 2007).

\section{Methods}

\section{Participants}

A total of 48 skilled, male defensive or defensive midfield soccer players (age $20.7 \pm 2.4$ years; mean $\pm s$ ) participated. Players were recruited from a range of different semi-professional soccer clubs in the United Kingdom. A second control group comprised of 16 amateur and recreationallevel defensive players (age $22.1 \pm 2.8$ years). Participants provided informed consent and the research procedures were conducted according to the ethical guidelines of the lead institution.

\section{Measures}

Perceptual-cognitive test. Participants were presented with life-size video sequences involving dynamic, 11 versus 11 soccer situations filmed and viewed from the perspective of a central defender. Further details on the production of the test film are reported elsewhere (see Roca, Ford, McRobert, \& Williams, 2011). The film contained 11 versus 9 (the defensive team's sweeper and goalkeeper were not involved) match play on a full-size pitch with skilled adult players. The viewing perspective of the video action provided a realistic correspondence (i.e., "firstperson" perspective) with the field of view that a central defensive player normally observes when playing in a match. The test film comprised of 20 video clips, with each one lasting approximately $5 \mathrm{~s}$, and being occluded at a key moment in the action (e.g., player in possession of the ball about to make an attacking pass, shoot at goal, or maintain possession of the ball by dribbling forward). The order of presentation of the clips was the same for all participants.

Questionnaire. The Participation History Questionnaire (PHQ) first used by Ford et al. (2010a) was used to trace the developmental activities undertaken by players. The questionnaire comprised of three different sections. The first section recorded information on soccer-specific milestones. These 
milestones were the age at which participants first took part in soccer (e.g., kicking around), supervised training in soccer with an adult, organised soccer league, and semi-professional soccer. The second section of the questionnaire elicited information on engagement in soccer-related activities. Three soccer activities were examined, namely, competition, practice and play. Competition referred to the time spent playing organised competitive matches against another team in which the intent is to win (e.g., league games). Practice referred to soccer activity undertaken alone or in a group under the supervision of coaches or adults in which the intent is to improve performance (e.g., practice with the team). Play activities referred to play-type games with rules supervised by participants themselves in which the intent is enjoyment (e.g., game of soccer in the park with friends). Participants provided the number of hours per week and the number of months per year spent in each of the soccer activities in each year of participation in the sport. Players were required to provide the number of weeks from each year they were injured and unable to participate in any soccerrelated activity. This information was reported retrospectively for the present season/year, then working backwards in two-year intervals until the age they first started playing soccer.

The final section of the questionnaire recorded information on engagement in other sporting activities. A list of sports was provided and participants were required to indicate which ones they had taken part in on a regular basis (i.e., a minimum period of at least 3 months) outside of school physical education classes during their development. The age at which they started and finished (unless they were still involved in the sport) playing each sport was recorded. Space was provided to include information on any sports they had participated in that were not on the list.

\section{Procedure}

The procedures were explained to the participants prior to commencing the tasks. Video clips were back projected onto a $2.7 \mathrm{~m}(\mathrm{~h}) \times 3.6 \mathrm{~m}(\mathrm{w})$ widescreen (Draper Cinefold, Spiceland, IN, USA) using a 3LCD video projection system (Hitachi ED-A101, Yokohama, Japan). Participants started $2.5 \mathrm{~m}$ away from the screen. They interacted and moved with the action sequence as they would normally do when playing in a "real-world" soccer match situation. At the end of each video clip, participants were required to confirm "What the player in possession was going to do?" and "What decision the participant themselves made or were about to make at the moment of video occlusion?" Participants completed four warm-up trials for familiarisation prior testing. The total duration of each individual test session was approximately $30 \mathrm{~min}$.

Following completion of the test, participants completed the PHQ in order to elicit information about their practice history profiles. Questionnaires were completed individually, under supervision and at a desk adjacent to the test setting. The experimenter provided verbal instructions on how to fill in the questionnaire and was available at all times to answer queries related to the interpretation and completion of the questionnaire. Participants took approximately $45 \mathrm{~min}$ to complete the questionnaire.

\section{Reliability}

The test-retest method was employed on a sample of five randomly selected participants to assess the reliability of retrospective responses to the questionnaire in terms of hours in soccer activities. The retest involved the PHQ being administrated to the subsample of participants three months after the first test. Two statistical methods were applied to assess measurement error. First, the relative reliability, which corresponds to the level of association between the two tests, was checked using an intraclass correlation (Atkinson \& Nevill, 1998; Thomas, Nelson, \& Silverman, 2005). Second, limits of agreement were used to examine the absolute reliability, which corresponds to the level of agreement between the two tests (Atkinson \& Nevill, 1998; Bland \& Altman, 2007). A large intraclass correlation coefficient was reported for the hours per week spent in each of the three different soccer activities, $R(104)=0.90$. The limits of agreement were $0.27 \pm 1.40 \mathrm{~h}, P>0.05$, confirming that there were no significant systematic errors between the test-retest.

\section{Data analysis}

The main dependent measures were the response accuracy scores for anticipation and decision making, respectively. Anticipation accuracy was defined as whether or not the participant correctly selected the next action of the player in possession of the ball at the moment of video occlusion (e.g., passed to a teammate and which teammate, shot at goal, or continued dribbling the ball). For the decision making measure, a panel of three Union of European Football Associations (UEFA) qualified soccer coaches independently selected the most appropriate decision for a participant to execute in response to the situation at the time of video occlusion on each trial. The accuracy was then defined as whether or not the participant decided on the action selected by the coaches as most appropriate for that trial. The inter-observer agreement between coach selections 
was $92 \%$. The anticipation and decision making accuracy were calculated as the mean number of trials (in \%) in which the participant made the correct response. The performance scores for both response accuracies were averaged into a combined test score for each participant.

Participation history profile data were analysed for two age periods (i) 6-12 years (i.e., childhood) and (ii) 13-18 years of age (i.e., adolescence) to match the developmental stages outlined by Côté (1999). The accumulated hours in soccer activity for each year between 6 and 18 years of age were calculated by multiplying hours reported per week by weeks per year, minus weeks per year players reported as being injured and unable to participate in soccer activities. The number of weeks per year was based on a 40week season for practice and competition. As per Ford and Williams (2008), linear interpolation was used to calculate missing data for each single year within each 2-year interval where no data were collected. The average hours per year in the three soccer activities across age categories were calculated by summing accumulated hours in each activity within a stage and then dividing by the number of years in that stage. The average hours per year in each of the three soccer activities as a function of the two age stages were used as the dependent variable in the subsequent inferential analyses.

First, a hierarchical multiple regression analysis was conducted on the average hours per year in the soccer activities as a function of stage for the 48 skilled participants only so as to determine which were most predictive of performance on the perceptual-cognitive test. The variables for soccer practice activity for adolescence and childhood were given priority at Step 1 and 2 respectively as we had hypothesised from existing literature that practice activity in the primary sport would co-occur and possibly contribute to the acquisition of anticipation and decision making (e.g., Ford et al., 2010a; Weissensteiner et al., 2008). At Step 3, soccerspecific play activity for childhood was entered as it had been predicted that the co-occurrence and possible contribution of this variable may account for the development of these two abilities (e.g., Ford et al., 2009). No a-priori hypotheses were formed regarding the remaining activities and so these variables were entered simultaneously in Step 4.

Second, two groups were created from the total sample of skilled players based on their combined scores from the perceptual-cognitive test. The top 16 ranked skilled players were classified as skilled highperforming, whereas players ranked in the bottom 16 of this group were classified as skilled low-performing. Players ranked in the middle 16 skilled participants were removed from this analysis. A third group $(n=16)$ classified as recreational was used as a control group. The combined scores from the perceptual-cognitive test were analysed using oneway analysis of variance (ANOVA) in which Group (skilled high-performing, skilled low-performing and recreational) was the between-participant factor. In this second analysis, the average hours per year in each of the three soccer activities were subjected to Group (skilled high-performing, skilled lowperforming and recreational) $\times$ Activities (competition, practice and play) ANOVAs with repeated measures on the last factor. The data for childhood and adolescence periods were analysed separately.

The milestones of start age in soccer, start age in supervised training with an adult, start age in organised soccer league, start age in elite training programme of a professional club, and start age in semi-professional soccer were analysed separately using one-way ANOVAs between the skilled highperforming, skilled low-performing and recreational groups. The number of other sports were analysed using separate one-way ANOVAs for each age period (i.e., childhood and adolescence) between groups (skilled high-performing, skilled low-performing and recreational). Any violations of sphericity were corrected using Greenhouse-Geisser and HuynhFeldt procedures. The effect sizes were calculated using partial eta squared $\left(\eta_{\mathrm{p}}{ }^{2}\right)$ values and Cohen's $d$ as appropriate. Any significant main and interaction effects were followed up using Bonferroni-corrected pairwise comparisons and Tukey's HSD post hoc tests, respectively. The alpha level required for significance for all tests was set at $P<0.05$.

\section{Results}

Skilled group

The response accuracy score for the perceptualcognitive test for the 48 skilled players was $69.9 \pm$ $8.8 \%$. The hierarchical multiple regression analysis in which the perceptual-cognitive test score was the criterion variable and the three soccer activities (competition, practice, and play) for (i) 6-12 years and (ii) 13-18 years of age the predictor variables produced significant equations for the first and third steps of the analysis (see Table I). The overall regression model accounted for $39.0 \%$ of the variance in perceptual-cognitive skill, $R^{2}=0.39$, $F_{6,41}=4.36, P<0.05$. In Step 1 , the average hours per year in practice in soccer for 13 to 18 years of age explained $13.2 \%$ of the variance for perceptual-cognitive performance accuracy, $F_{\text {change1, } 46}=$ $6.96, P<0.05$. When average hours per year in soccer-specific practice for 6-12 years of age was entered in the second step of the analysis, it did not significantly improve prediction accuracy, $F_{\text {change1, 45 }}=0.15, P>0.05$. In Step 3, inclusion 
of average hours per year in soccer play activity for childhood increased explained variance by a further $21.8 \%, F_{\text {change } 1,44}=14.80, P<0.001$. In the final step, when the remaining soccer activities (i.e., competition during childhood, play during adolescence, and competition during adolescence) were entered they did not produce any significant change on the overall model's variance, $F_{\text {change } 3,41}=0.84$, $P>0.05$.

Table I. The summary of hierarchical regression analysis for soccer activity variables predicting perceptual-cognitive skill.

\begin{tabular}{lrrr}
\hline Predictor variables & \multicolumn{1}{c}{$B$} & $S E B$ & $\beta$ \\
\hline Step 1 & & & \\
Constant & 61.03 & 3.59 & \\
Practice (13-18 years) & 0.06 & 0.02 & $0.36^{\star}$ \\
Step 2 & & & \\
Constant & 61.52 & 3.84 & \\
Practice (13-18 years) & 0.06 & 0.02 & $0.38^{\star}$ \\
Practice (6-12 years) & -0.02 & 0.04 & -0.06 \\
Step 3 & & & \\
Constant & 53.91 & 3.90 & \\
Practice (13-18 years) & 0.04 & 0.02 & 0.23 \\
Practice (6-12 years) & -0.03 & 0.03 & -0.12 \\
Play (6-12 years) & 0.05 & 0.01 & $0.50^{\star \star \star}$ \\
Step 4 & & & \\
Constant & 52.56 & 5.08 & \\
Practice (13-18 years) & 0.04 & 0.02 & 0.25 \\
Practice (6-12 years) & -0.08 & 0.05 & -0.31 \\
Play (6-12 years) & 0.05 & 0.01 & $0.54^{\star \star}$ \\
Play (13-18 years) & 0.00 & 0.02 & 0.02 \\
Competition (13-18 years) & -0.01 & 0.04 & -0.04 \\
Competition (6-12 years) & 0.11 & 0.07 & 0.27 \\
\hline
\end{tabular}

Note: $R^{2}=0.13$ for Step $1 ; \Delta R^{2}=0.00$ for Step $2 ; \Delta R^{2}=0.22$ for Step 3; $\Delta R^{2}=0.04$ for Step 4 .

${ }^{\star} P<0.05,{ }^{\star \star} P<0.01$, and ${ }^{\star \star \star} P<0.001$.
Skilled high-versus low-performing versus recreational groups

Perceptual-cognitive performance. There was a significant difference between groups for response accuracy on the perceptual-cognitive test, $F_{2,45}=$ 240.93, $P<0.001, \eta_{\mathrm{p}}{ }^{2}=0.92$. The skilled highperforming players $(80.0 \pm 3.7 \%)$ recorded higher scores on the perceptual-cognitive test compared with the skilled low-performing $(60.3 \pm 4.6 \%)$ and recreational groups $(42.8 \pm 5.8 \%)$. Also, the skilled low-performing scored significantly higher than the recreational group.

Milestones. The descriptive and inferential statistics for each group's milestones are presented in Table II. No differences were found between the skilled highperforming, skilled low-performing and recreational groups for their chronological age and for the milestones of start age in soccer, in supervised training in soccer or in an organised soccer league. There were also no differences between the skilled high-performing and low-performing groups for the age they first engaged in an elite training programme and later on reached an adult semi-professional level. Recreational players did not achieve either of these two milestones.

Soccer activity. Figure 1 presents the average hours per year between 6 and 18 years of age in the three soccer activities for the skilled high-performing, skilled lowperforming, and recreational groups. The statistical analyses for average hours per year in soccer activity during childhood are presented in Table III. The average hours per year in soccer activity during childhood were significantly higher for the skilled high-performing $\left(449.2 \pm 146.5 \mathrm{~h} \cdot\right.$ year $\left.^{-1}\right)$ players

Table II. The statistical and descriptive analyses for soccer milestones (in years).

\begin{tabular}{|c|c|c|c|c|c|}
\hline Variable and comparison & $M S$ & MSE & $F$ & $\eta_{p}^{2}$ & Mean $\pm s$ \\
\hline Chronological age $^{\mathrm{a}}$ & 12.27 & 7.14 & 1.72 & 0.07 & $\begin{array}{l}\text { Skilled high-performing }=20.9 \pm 3.1 \\
\text { Skilled low-performing }=20.5 \pm 2.0 \\
\text { Recreational }=22.1 \pm 2.8\end{array}$ \\
\hline \multicolumn{6}{|l|}{ Start ages } \\
\hline In soccer ${ }^{a}$ & 0.90 & 1.47 & 0.61 & 0.03 & $\begin{array}{l}\text { Skilled high-performing }=5.2 \pm 1.3 \\
\text { Skilled low-performing }=5.6 \pm 1.1 \\
\text { Recreational }=5.5 \pm 1.2\end{array}$ \\
\hline In supervised training ${ }^{\mathrm{a}}$ & 1.65 & 4.15 & 0.40 & 0.02 & $\begin{array}{l}\text { Skilled high-performing }=7.5 \pm 1.9 \\
\text { Skilled low-performing }=8.0 \pm 2.2 \\
\text { Recreational }=7.9 \pm 1.9\end{array}$ \\
\hline In soccer league ${ }^{a}$ & 1.67 & 3.42 & 0.49 & 0.03 & $\begin{array}{l}\text { Skilled high-performing }=8.5 \pm 2.0 \\
\text { Skilled low-performing }=8.9 \pm 1.9 \\
\text { Recreational }=9.3 \pm 1.3\end{array}$ \\
\hline In elite training programme $\mathrm{e}^{\mathrm{b}}$ & 6.47 & 10.21 & 0.63 & 0.04 & $\begin{array}{l}\text { Skilled high-performing }(\mathrm{n}=11)=12.2 \pm 2.6 \\
\text { Skilled low-performing }(\mathrm{n}=8)=11.0 \pm 3.9\end{array}$ \\
\hline At semi-professional level ${ }^{c}$ & 0.03 & 2.12 & 0.02 & 0.00 & $\begin{array}{l}\text { Skilled high-performing }=17.6 \pm 1.7 \\
\text { Skilled low-performing }=17.6 \pm 1.2\end{array}$ \\
\hline
\end{tabular}

Note: ${ }^{\mathrm{a}} d f=(2,45) ;{ }^{\mathrm{b}} d f=(1,17) ;{ }^{\mathrm{c}} d f=(1,30)$. 

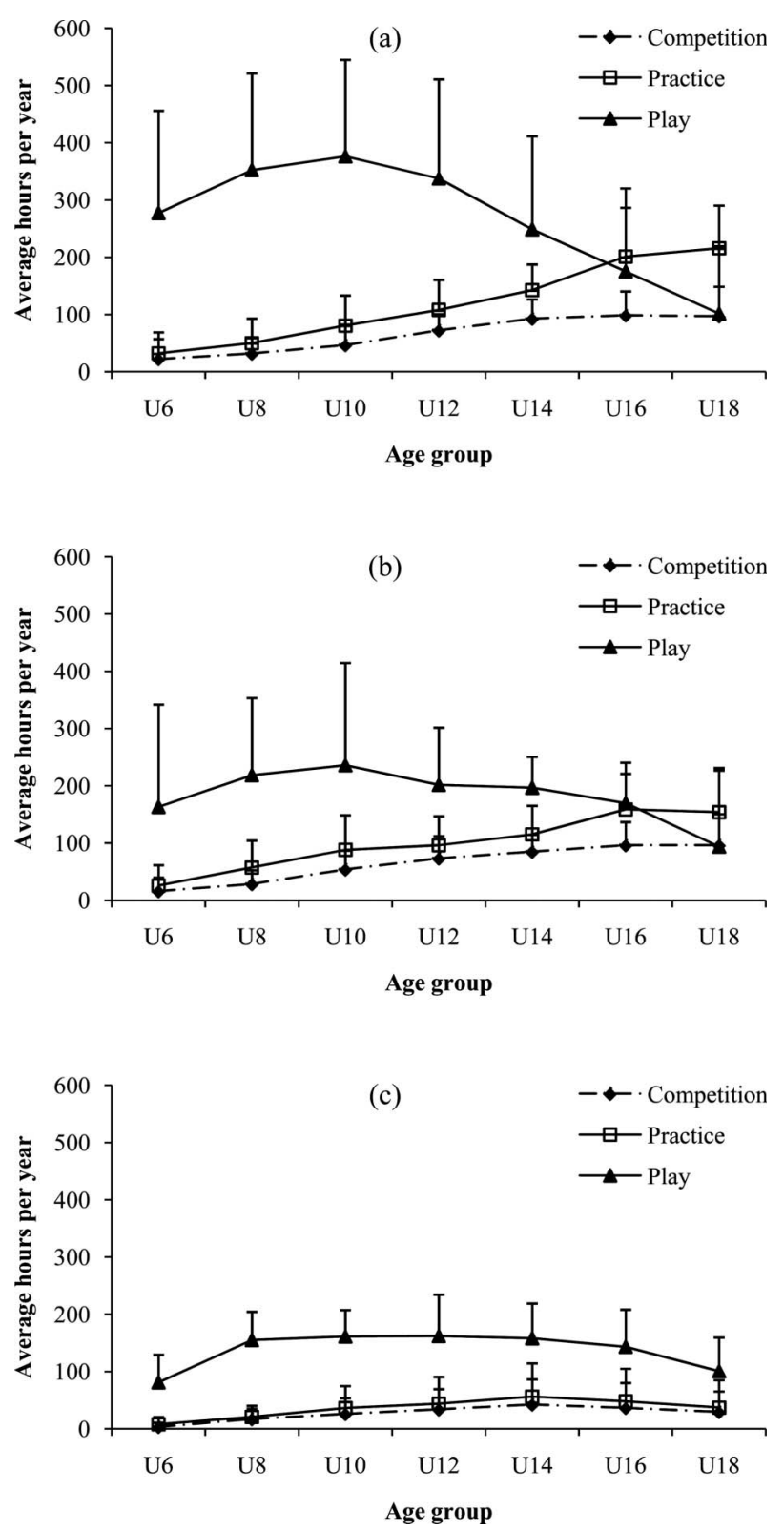

Figure 1. The Average hours per year between 6 and 18 years of age in each of three soccer activities (competition, practice, play) for (a) skilled high-performing, (b) skilled low-performing and (c) recreational players.

compared with the other two groups. Moreover, the average hours per year in soccer activity for skilled low-performing players $\left(317.4 \pm 69.6 \mathrm{~h} \cdot\right.$ year $\left.^{-1}\right)$ was significantly higher when compared to the recreational players $\left(190.1 \pm 65.1 \mathrm{~h} \cdot\right.$ year $\left.^{-1}\right)$. The average hours per year in soccer play activities $\left(229.7 \pm 106.1 \mathrm{~h} \cdot\right.$ year $\left.^{-1}\right)$ during this period were greater than those in the other two types of activity. The skilled high-performing group (339.0 \pm $125.4 \mathrm{~h} \cdot$ year $^{-1}$ ) spent significantly more average hours per year in soccer-specific play activity in comparison with the other two groups. The skilled low-performing group $\left(207.6 \pm 50.6 \mathrm{~h} \cdot\right.$ year $\left.^{-1}\right)$
Table III. The statistical analyses of separate ANOVAs on average hours per year in soccer activity.

\begin{tabular}{lcccc}
\hline $\begin{array}{l}\text { Variable and } \\
\text { comparison }\end{array}$ & MS & MSE & $F$ & $\eta_{p}{ }^{2}$ \\
\hline Average hours per year (6-12 years) & & & \\
$\quad$ Group & $89,529.75$ & $3,392.72$ & $26.39^{\star \star \star}$ & 0.54 \\
Activity & $983,579.03$ & $4,331.34$ & $227.08^{\star \star \star}$ & 0.84 \\
Group $\times$ Activity & $73,090.28$ & $4,331.34$ & $16.88^{\star \star \star}$ & 0.43 \\
Average hours per year $(13-18$ years) & & \\
Group & $82,855.89$ & $3,610.87$ & $22.95^{\star \star \star}$ & 0.51 \\
Activity & $107,347.69$ & $2,274.30$ & $47.20^{\star \star \star}$ & 0.51 \\
Group $\times$ Activity & $9,391.26$ & $2,274.30$ & $4.13^{\star \star}$ & 0.16 \\
\hline
\end{tabular}

Note: $d f=(2,45)$.

${ }^{\star} P<0.05,{ }^{\star \star} P<0.01$, and ${ }^{\star \star \star} P<0.001$.

engaged in a greater number of average hours per year in soccer-specific play activities compared with the recreational players $\left(142.4 \pm 39.5 \mathrm{~h} \cdot\right.$ year $\left.^{-1}\right)$. The average hours per year in practice activity $\left(54.0 \pm 35.7 \mathrm{~h} \cdot\right.$ year $\left.^{-1}\right)$ were greater than those in competition $\left(35.3 \pm 23.7 \mathrm{~h} \cdot\right.$ year $\left.^{-1}\right)$ (see Figure 1$)$.

The statistical analyses for average hours per year in soccer activity during adolescence are displayed in Table III. There were no significant differences for the average hours per year in soccer activity during this period between the skilled high-performing $\left(467.1 \pm 92.3 \mathrm{~h} \cdot\right.$ year $\left.^{-1}\right)$ and skilled low-performing $\left(390.3 \pm 105.2 \mathrm{~h} \cdot\right.$ year $\left.^{-1}\right)$ groups. However, these two groups engaged in a greater number of average hours per year in soccer when compared with the recreational group $\left(223.3 \pm 113.7 \mathrm{~h} \cdot\right.$ year $\left.^{-1}\right)$. The average hours per year in soccer-specific play activity $\left(165.4 \pm 65.1 \mathrm{~h} \cdot\right.$ year $\left.^{-1}\right)$ during this period were greater compared to the other two activity types. The average hours per year in practice activity $\left(121.0 \pm 69.6 \mathrm{~h} \cdot\right.$ year $\left.^{-1}\right)$ were greater than those in competition $\left(73.8 \pm 41.8 \mathrm{~h} \cdot\right.$ year $\left.^{-1}\right)$. A significantly greater number of average hours per year were spent in both soccer practice and competition activities by both skilled high-performing (178.1 $\pm 54.6 \mathrm{~h}$. year $^{-1}$ and $94.2 \pm 31.2 \mathrm{~h} \cdot$ year $^{-1}$, respectively) and skilled low-performing groups $(137.4 \pm 44.4 \mathrm{~h}$. year $^{-1}$ and $90.7 \pm 31.2 \mathrm{~h} \cdot$ year $\left.^{-1}\right)$ when compared with the recreational players $\left(47.7 \pm 48.2 \mathrm{~h} \cdot\right.$ year $^{-1}$ and $36.6 \pm 37.7 \mathrm{~h} \cdot$ year $\left.^{-1}\right)$. Moreover, the skilled high-performing group $\left(194.8 \pm 57.6 \mathrm{~h} \cdot\right.$ year $\left.^{-1}\right)$ engaged in more hours per year during adolescence in soccer-specific play activity in comparison with the recreational group $\left(139.1 \pm 52.3 \mathrm{~h} \cdot\right.$ year $^{-1}$ ) (see Figure 1). A one-way ANOVA revealed that by 18 years of age, the skilled high-performing players $(5946.9 \pm 1469.7 \mathrm{~h})$ had accumulated more total hours in soccer activity compared to their skilled lowperforming counterparts $(4563.7 \pm 768.9 \mathrm{~h})$, with both groups accumulating more hours compared to the recreational group $(2670.4 \pm 1075.0 \mathrm{~h}), F_{1,45}=$ 33.24, $P<0.001, \eta_{\mathrm{p}}{ }^{2}=0.60$. 
Other sports activity. Start age in other sports did not differentiate the skilled high-performing $(11.5 \pm 2.3$ years of age), skilled low-performing (10.8 \pm 1.7 years of age) and recreational groups (11.1 \pm 2.1 years of age), $F_{2,43}=0.47, P>0.05, \eta_{\mathrm{p}}{ }^{2}=0.02$. The number of other sports engaged in during childhood did not differentiate the skilled highperforming ( $2.1 \pm 1.8$ sports), skilled low-performing $(2.2 \pm 1.7$ sports $)$ and recreational groups $\left(2.2 \pm 1.2\right.$ sports), $F_{2,45}=0.03, P>0.05, \eta_{\mathrm{p}}{ }^{2}=$ 0.00 . The number of other sports during adolescence did not differentiate the skilled high-performing $(2.7 \pm 1.4$ sports), skilled low-performing (2.4 \pm 1.6 sports $)$ and recreational groups $(2.6 \pm 1.3$ sports), $F_{2,45}=0.20, P>0.05, \eta_{\mathrm{p}}{ }^{2}=0.01$. The most popular other sports for the skilled highperforming players were athletics and basketball ( $n=7$ players), whereas for the skilled low-performing players these were swimming $(n=5)$, athletics, badminton and basketball ( $n=4$ players each). For the recreational group, judo $(n=6)$ and cricket $(n=5)$ were the most popular other sports.

\section{Discussion}

We examined whether soccer players who were differentiated statistically based on their scores on a test that evaluated their ability to anticipate and make decisions (e.g., high- or low-performing) could be differentiated by the type and amount of activities that they had engaged in during their development. The participation history profiles of players were recorded using an established retrospective recall questionnaire.

As predicted, there were no between-group differences for milestones achieved, such as the start age in soccer (mean 5 years), age at which players first took part in supervised training in soccer with an adult (mean 8 years) and, age at which they started playing in an organised soccer league (mean 9 years). The age at which these milestones were achieved did not differ to those reported in previous research with soccer players (Ford et al., 2009; Ford \& Williams, 2012; Helsen et al., 1998; Ward et al., 2007). Also, as predicted, the average hours per year in soccerspecific play activity during childhood explained a moderate amount $(21.8 \%)$ of the variance in test scores and differentiated skill groups. These findings provide support for Ford et al. (2009) who showed that the average hours per year during childhood in soccer play activity was the only activity to differentiate elite youth players who progressed to professional status in adulthood from those who engaged in less of that activity and did not progress. The skilled high-performing group were engaging in around $339 \mathrm{~h} \cdot$ year $^{-1}$ of this activity during childhood, which is comparable with the $338 \mathrm{~h} \cdot$ year $^{-1}$ (or $7 \mathrm{~h} \cdot$ week $^{-1}$ across a 50 -week year) reported by Ford et al. (2009) for elite youth players in England who progressed to professional status. The skilled low-performing group averaged more hours per year in soccer-specific play activity when compared with the recreational group. The skilled low-performing group were engaging in $208 \mathrm{~h} \cdot$ year $^{-1}$ of this activity during childhood, which is slightly greater than the $148 \mathrm{~h} \cdot$ year $^{-1}$ reported by Ford et al. (2009) for elite youth players in England who did not progress to professional status. Moreover, recreational players in the current study engaged in this activity for $142 \mathrm{~h}$. year ${ }^{-1}$ compared to the $158 \mathrm{~h} \cdot$ year $^{-1}$ reported by Ford et al. (2009). The co-occurrence of greater amounts of soccer play activity during childhood within successively higher skill groups suggests that this activity may contribute to anticipation and decision making ability.

In line with our predictions, during adolescence, the average hours per year in soccer practice activity explained some of the variance $(13.2 \%)$ in anticipation and decision making ability. This later observation partly supports findings reported by Weissensteiner et al. (2008) who showed that hours accumulated in formal activities in cricket was the main contributor to the variance $(11-13 \%)$ in performance on an anticipation test. Weissensteiner and colleagues (2008) did not separate their analysis into developmental age stages and their formal cricket activities included both practice and competition. In the present study, although no activity differences were apparent between skilled high- and low-performing players, both groups took part in significantly more hours per year in soccer-specific practice and competition activities during adolescence compared to their recreational counterparts. These results support those reported by Ford et al. (2010a), Ward et al. (2007) and Weissensteiner et al. (2008), with skilled groups accumulating significantly more hours per year in structured soccer activities during adolescence. The skilled high- and low-performing groups were engaging in around 3 to $5 \mathrm{~h} \cdot$ week $^{-1}$ of soccer practice activity during adolescence, which is lower than the 5 to $9 \mathrm{~h} \cdot$ week $^{-1}$ reported for international soccer players during adolescence (Helsen et al., 1998), although players in the latter study attained a higher level of participation. No other soccer activities in either stage contributed to the test scores. However, the between-group differences observed in the different types of soccer activity led to the hours accumulated in all soccer activity by 18 years of age differentiating groups in the predicted manner. It is possible that simply accumulating more hours in the sport may have led to superior performance on the test. In previous research where between-group differences are observed in a specific type of soccer activity, this 
has led to differences in the hours accumulated in all soccer activity (e.g., Ford et al., 2010a).

The three skill groups were not predicted to be differentiated based on their engagement in other sports, which was expected to be low across childhood and adolescence (e.g., Ward et al., 2007). Players participated in a mean number of two other sports during childhood, which they mainly started participating in at secondary school age (mean start age 11 years). This finding contradicts the previous research of Berry et al. (2008) who showed that engaging in other related sports is associated to better decision making in the primary sport. We speculate that the skilled high-performing group was following the "early engagement" pathway proposed by Ford et al. (2009). This pathway is defined by athletes participating mainly in deliberate play in the primary sport during childhood, engaging in limited or no other sports activity, participating in some deliberate practice in the primary sport during childhood, and late or delayed (i.e., 13 to 15 years of age) engagement in large amounts of deliberate practice in the primary sport. It is hypothesised that engagement in sport-specific play during childhood as outlined in the early engagement pathway is a key part of the development of perceptual and cognitive skills in soccer. We speculate that during play activity there may be significant opportunities for players to engage in situations that require continuous anticipation and creative/tactical decision making leading to specific adaptations in these abilities that transfer to competition and match play performance.

The use of retrospective recall data has the potential for memory/recall bias by participants (Hodges, Huys, \& Starkes, 2007). Moreover, the co-occurrence of high amounts of a particular activity and higher anticipation and decision making ability does not show or infer that the activity caused the ability. A range of other factors contribute to expert performance, such as the microstructure of practice (Ford et al., 2010b) and these may play a role in the development of these abilities. In future, traditional experimental designs with controlled training interventions may be applied for this purpose in an effort to explore causal links between engagement in certain types of practice activities and/ or the strategies employed (e.g., instructional processes) and specific changes/adaptations in particular performance attributes such as the decision making skill. In addition, a more sophisticated micro-level analysis of these specific practice and instructional activities "in situ", through detailed time-use video analysis, may help to identify and better understand the nature of these types of activities in soccer and across other sports (e.g., see Ford et al., 2010b).

In summary, we categorised skilled players into high- or low-performing groups based on their scores on a test of anticipation and decision making. We examined whether these groups could be differentiated in regard to the amount and type of activities in which they had participated during development. The average hours per year in soccer-specific play activity during childhood was the strongest predictor of performance on the perceptual-cognitive test and differentiated the skill groups. We hypothesise that soccer-specific play activity during childhood provides the conditions for players to engage in anticipation and decision making leading to lasting adaptations and improvements in these abilities. Soccer-specific practice activity during adolescence was also a contributing factor to the variance in anticipation and decision making scores across participants, supporting previous work in cricket (Ford et al., 2010a; Weissensteiner et al., 2008). No differences across groups were reported for number of other sports engaged in during development or some of the key milestones achieved.

\section{Acknowledgments}

The lead author was funded by the Portuguese Foundation for Science and Technology (FCT) Ministry of Education and Science (MEC; Ref. SFRH/BD/35748/2007).

\section{References}

Atkinson, G., \& Nevill, A. M. (1998). Statistical methods for assessing measurement error (reliability) in variables relevant to sports medicine. Sports Medicine (Auckland, N.Z.), 26, 217-238.

Berry, J., Abernethy, B., \& Côté, J. (2008). The contribution of structured activity and deliberate play to the development of expert perceptual and decision-making skill. Fournal of Sport $\mathbb{E}$ Exercise Psychology, 30, 685-708.

Bland, J. M., \& Altman, D. G. (2007). Agreement between methods of measurement with multiple observations per individual. Fournal of Biopharmaceutical Statistics, 17, 571-582.

Côté, J. (1999). The influence of the family in the development of talent in sport. The Sport Psychologist, 13, 395-417.

Côté, J., Ericsson, K. A., \& Law, M. P. (2005). Tracing the development of athletes using retrospective interview methods: A proposed interview and validation procedure for reported information. Fournal of Applied Sport Psychology, 17, 1-19.

Côté, J., \& Hay, J. (2002). Children's involvement in sport: A developmental perspective. In J. M. Silva \& D. Stevens (Eds.), Psychological foundations of sport (pp. 484-502). Boston, MA: Merrill.

Ericsson, K. A. (2003). Development of elite performance and deliberate practice. In J. L. Starkes \& K. A. Ericsson (Eds.), Expert performance in sports. Advances in research on sport expertise (pp. 49-83). Champaign, IL: Human Kinetics.

Ericsson, K. A. (2007a). Deliberate practice and the modifiability of body and mind: Toward a science of the structure and acquisition of expert and elite performance. International fournal of Sport Psychology, 38, 4-43.

Ericsson, K. A. (2007b). Toward a science of expert and exceptional performance in Sport: A reply to the Commentaries. International fournal of Sport Psychology, 38, 109-123.

Ericsson, K. A., Krampe, R. T., \& Tesch-Römer, C. (1993). The role of deliberate practice in the acquisition of expert performance. Psychological Review, 100, 363-406. 
Ericsson, K. A., Nandagopal, K., \& Roring, R. W. (2009). Toward a science of exceptional achievement: Attaining superior performance through deliberate practice. Annals of New York Academy of Science, 1172, 199-217.

Ford, P. R., Low, J., McRobert, A. P., \& Williams, A. M. (2010a). Developmental activities that contribute to high or low performance by elite cricket batters when recognising type of deliveries from bowlers' advanced postural cues. Fournal of Sport E Exercise Psychology, 32, 638-654.

Ford, P. R., Ward, P., Hodges, N. J., \& Williams, A. M. (2009). The role of deliberate practice and play in career progression in sport: The early engagement hypothesis. High Ability Studies, 20, 65-75.

Ford, P. R., \& Williams, A. M. (2008). The effect of participation in Gaelic football on the development of Irish professional soccer players. Fournal of Sport E Exercise Psychology, 30, 709 722.

Ford, P. R., \& Williams, A. M. (2012). The developmental activities engaged in by elite youth soccer players who progressed to professional status compared to those who did not. Psychology of Sport and Exercise, 13, 349-352.

Ford, P. R., Yates, I., \& Williams, A. M. (2010b). An analysis of practice activities and instructional behaviours used by youth soccer coaches during practice: Exploring the link between science and application. Fournal of Sports Sciences, 28, 483-495.

Helsen, W. F., \& Starkes, J. L. (1999). A multidimensional approach to skilled perception and performance in sport. Applied Cognitive Psychology, 13, 1-27.

Helsen, W. F., Starkes, J. L., \& Hodges, N. J. (1998). Team sports and the theory of deliberate practice. Fournal of Sport $\&$ Exercise Psychology, 20, 12-34.

Hodges, N. J., Huys, R., \& Starkes, J. L. (2007). Methodological review and evaluation of research in expert performance in sport. In G. Tenenbaum \& R. C. Eklund (Eds.), Handbook of sport psychology (3rd ed.) (pp. 161-183). New York, NY: Wiley.
Reilly, T., Williams, A. M., Nevill, A., \& Franks, A. (2000). A multidisciplinary approach to talent identification in soccer. Fournal of Sports Sciences, 18, 668-676.

Roca, A., Ford, P. R., McRobert, A. P., \& Williams, A. M. (2011). Identifying the processes underpinning anticipation and decision-making in a dynamic time-constrained task. Cognitive Processing, 12, 301-310.

Thomas, J. R., Nelson, J. K., \& Silverman, S. J. (2005). Research methods in physical activity (5th ed.). Champaign, IL: Human Kinetics.

Vaeyens, R., Lenoir, M., Williams, A. M., Mazyn, L., \& Philippaerts, R. M. (2007). Mechanisms underpinning successful decision making in skilled youth soccer players: An analysis of visual search behaviours. Fournal of Motor Behavior, 39, 395-408.

Ward, P., Hodges, N. J., Starkes, J., \& Williams, A. M. (2007). The road to excellence: Deliberate practice and the development of expertise. High Ability Studies, 18, 119-153.

Weissensteiner, J., Abernethy, B., Farrow, D., \& Müller, S. (2008). The development of anticipation: A cross-sectional examination of the practice experiences contributing to expertise in cricket batting. Fournal of Sport \& Exercise Psychology, 30, 663-684.

Williams, A. M., \& Davids, K. (1998). Visual search strategy, selective attention, and expertise in soccer. Research Quarterly for Exercise and Sport, 69, 111-128.

Williams, A. M., Ford, P. R., Eccles, D. W., \& Ward, P. (2011). Perceptual-cognitive expertise in sport and its acquisition: Implications for applied cognitive psychology. Applied Cognitive Psychology, 25, 432-442.

Williams, A. M., \& Reilly, T. (2000). Talent identification and development in soccer. Fournal of Sports Sciences, 18, 657-667.

Williams, A. M., \& Ward, P. (2007). Anticipation and decision making: Exploring new horizons. In G. Tenenbaum \& R. C. Eklund (Eds.), Handbook of sport psychology (3rd ed.) (pp. 203223). Hoboken, NJ: John Wiley \& Sons. 